University of Wollongong

Research Online

Faculty of Engineering and Information

Faculty of Engineering and Information

Sciences - Papers: Part A

Sciences

$1-1-2014$

Development of high melting temperature microencapsulated phase change material for compacted thermal energy storage bed

Weiguang Su

University of Nottingham

Jo Darkwa

University of Nottingham

Georgios Kokogiannakis

University of Wollongong, gkg@uow.edu.au

Follow this and additional works at: https://ro.uow.edu.au/eispapers

Part of the Engineering Commons, and the Science and Technology Studies Commons

Research Online is the open access institutional repository for the University of Wollongong. For further information contact the UOW Library: research-pubs@uow.edu.au 


\title{
Development of high melting temperature microencapsulated phase change material for compacted thermal energy storage bed
}

\author{
Abstract \\ In this paper a novel high temperature microencapsulated phase change material (MEPCM) based on \\ paraffin as the core material and MF resin as the shell material has been developed with the in-situ \\ polymerization method for solar hot water storage application. The results showed that the type of \\ emulsifier could influence core material content, the encapsulation efficiency as well as the latent heat \\ capacity. Based on the results and analysis the study has shown that energy storage density could be \\ increased by as much as $59 \%$ if $60 \mathrm{wt} \%$ of MEPCM 1 was to be used in the proposed compacted MEPCM- \\ water bed system.

\section{Keywords} \\ development, phase, change, material, compacted, thermal, energy, storage, bed, melting, temperature, \\ high, microencapsulated

\section{Disciplines \\ Engineering | Science and Technology Studies}

\section{Publication Details} \\ Su, W., Darkwa, J. \& Kokogiannakis, G. (2014). Development of high melting temperature \\ microencapsulated phase change material for compacted thermal energy storage bed. 12th Annual \\ International Energy Conversion Engineering Conference (IECEC 2014) (pp. 756-763). United States: The \\ American Institute of Aeronautics and Astronautics (AIAA).
}




\title{
Development of high melting temperature microencapsulated phase change material for compacted thermal energy storage bed
}

\author{
W. Su ${ }^{1}$, J. Darkwa ${ }^{2}$, G. Kokogiannakis ${ }^{3}$ \\ Centre for Sustainable Energy Technologies (CSET) \\ University of Nottingham Ningbo China, 199 Taikang East Road, Ningbo 315100, China
}

\begin{abstract}
In this paper a novel high temperature microencapsulated phase change material (MEPCM) based on paraffin as the core material and MF resin as the shell material has been developed with the in-situ polymerization method for solar hot water storage application. The results showed that the type of emulsifier could influence core material content, the encapsulation efficiency as well as the latent heat capacity. Based on the results and analysis the study has shown that energy storage density could be increased by as much as $59 \%$ if $60 \mathrm{wt} \%$ of MEPCM 1 was to be used in the proposed compacted MEPCM-water bed system.
\end{abstract}

\begin{tabular}{ll} 
& \multicolumn{1}{c}{ Nomenclature } \\
$H_{\mathrm{PCM}}$ & $=$ latent heat of PCM \\
$H$ & $=$ enthalpy \\
$w t_{w}, w t_{P C M}, w t_{s}$ & $=$ the weight percentage of water, core material and shell material \\
$C p_{w}, C p_{P C M}, C p_{s}$ & $=$ the specific heat of water, core material and shell material \\
$k_{m}, k_{P C M}, k_{s}$ & $=$ the conductivity of water, paraffin and shell material \\
$\varphi_{s}, \varphi_{P C M}$ & $=$ the volume percentage of shell material and core material
\end{tabular}

\section{Introduction}

$S^{\circ}$ lar hot water systems are considered to be cost effective and efficient ways of providing hot water supply in buildings. However current systems use water as sensible heat storage medium which is simple and inexpensive, but require large amount of storage material and valuable space. These systems also undergo buoyancy dependent stratification which tends to affect heat transfer processes. Various researchers have therefore explored the possibility of using phase change materials (PCMs) as storage media since they have much larger heat storage capacities than sensible heat materials [1-4]. However, repeated thermal cycling of pure PCMs does result in some drawbacks. For instance the experiment conducted on a pure PCM storage tank by López-Navarro et al. [5] showed a much lower heat transfer efficiency after a number of thermal cycling and was attributed to low thermal conductivity of pure PCM and longer storage/discharge time of more than 4 hours. In another study, the melting point of the PCM (Rubitherm-21) shifted from 21 to $28^{\circ} \mathrm{C}$ [6] after 120 repeated experimental days which affected its stability for long term usage. Experiment by Chen et al.[7] also showed that huge thermal stress caused by large density change during phase change period and pressure drop reduced volume of the PCM tanker by $13.65 \%$.

In order to overcome these disadvantages other researchers suggested the use of microencapsulated PCM (MEPCM) instead of pure PCM [8, 9]. For instance, Ho et al. [10] investigated a fixed bed energy storage system containing 55

\footnotetext{
${ }^{1} \mathrm{PhD}$ candidate, Centre for Sustainable Energy Technologies (CSET), University of Nottingham Ningbo China, 199 Taikang East Road, Ningbo 315100, China /Weiguang.SU@ nottingham.edu.cn

${ }^{2}$ Professor, Centre for Sustainable Energy Technologies (CSET), University of Nottingham Ningbo China, 199 Taikang East Road, Ningbo 315100, China /Jo.DARKWA @ nottingham.edu.cn.

${ }^{3}$ Dr, Centre for Sustainable Energy Technologies (CSET), University of Nottingham Ningbo China, 199 Taikang

East Road, Ningbo 315100, China / Georgios.KOKOGIANNAKIS@ nottingham.edu.cn.
} 
$\mathrm{v} \%$ of MEPCM and achieved some positive results. In this study, a similar TES unit but consisting of compacted saturated water fixed bed MEPCM as thermal energy storage media (see Fig 1) was investigated for solar hot water supply system.

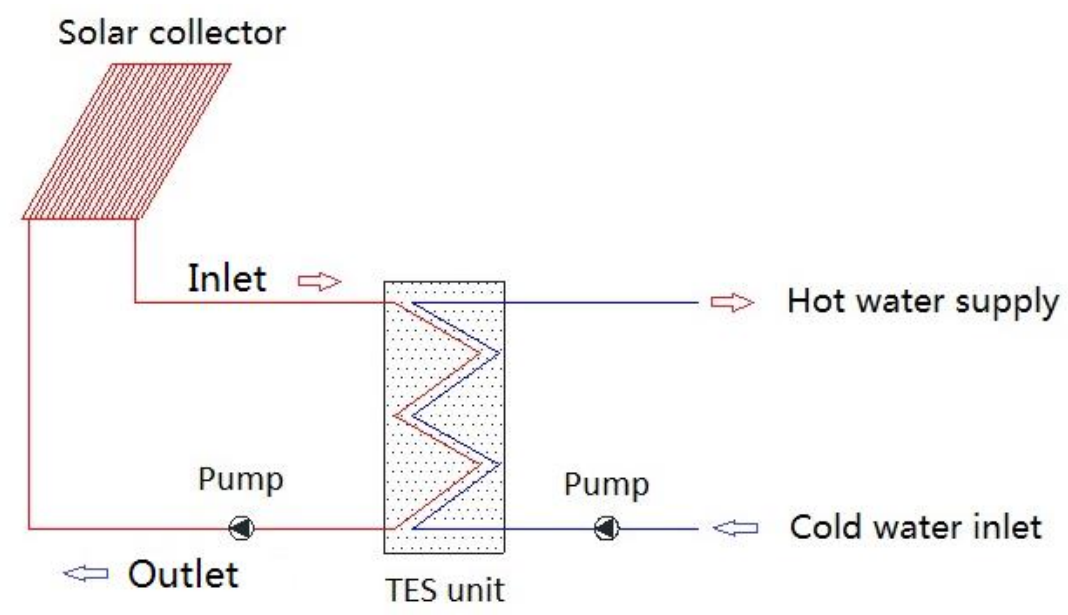

Figure 1: Compacted MEPCM bed system for solar assisted hot water supply

\section{Development of MEPCM}

\section{A. Material selection}

Due to its high latent heat and suitable phase change temperature paraffin was chosen as the base material for the development of the MEPCM. Appropriate sample with melting temperature at $48^{\circ} \mathrm{C}$ was therefore obtained from Dalian Longxing new material, Ltd. Melamine-formaldehyde resin (MF) have been reported as probably the most widely used shell materials for encapsulation processes and also have the ability to be crosslinked at different melamine/formaldehyde molecular ratios such as:1:1.25-2 [11], 1:2.66 [12] and 1:2.5 [13]). Therefore melamine with 99\% purity and $37 \mathrm{wt} \%$ formaldehyde solution were obtained from Sinopharm Chemical Reagent Co.,Ltd and used as shell monomers. Sodium dodecyl sulfate (SDS; Sinopharm Chemical Reagent Co.,Ltd, China; purity 90\%) and Brij 58 (Alfa, USA) + Brij 30 (Aladdin, Japan) were used as dispersants. Citric acid (Sinopharm Chemical Reagent Co.,Ltd, China) and sodium hydroxide (Sinopharm Chemical Reagent Co.,Ltd, China) solution were used to control the $\mathrm{pH}$ values during the experimental process. Ammonium chloride (purity 99.5\%) also supplied by Sinopharm Chemical Reagent Co.,Ltd. was used as a nucleating agent whereas deionized water was applied for dilution processes.

\section{B. Development of MEPCM}

The fabrication of the MEPCM was based on in-situ polymerization method as well as processes covering synthesisation of prepolymer solution, preparation of $\mathrm{O} / \mathrm{W}$ emulsion and formation of shells. As shown in Fig. 2 under Step 1, the prepolymer was prepared at $\mathrm{pH}$ value of 8.5-9. Melamine (4.04g) and 37\% formaldehyde solution $(6.5 \mathrm{~g})$ were initially mixed with $10 \mathrm{ml}$ deionized water at a stirring speed of $200 \mathrm{rpm}$. The blended mixture was then was heated up to $70^{\circ} \mathrm{C}$ and maintained at that reaction temperature until the suspension became transparent.

The value of hydrophilic-lipophilic balance (HLB) [14] of surfactant is one of the most important factors for preparing a stable oil-in-water $(\mathrm{O} / \mathrm{W})$ emulsion. In this development an appropriate value of 12 for the composite nonionic emulsifiers was used to produce the $\mathrm{O} / \mathrm{W}$ emulsion. Therefore Brij 30 and Brij 58 were mixed together and compared with the SDS emulsifiers listed in Tab.1. The mixture was then dispersed at a stirring rate of 7000rpm for 10min with a high speed dispersion machine (IKA T18, Germany) to form a stable O/W emulsion.

In order to fabricate MEPCM, capsules need to crosslink with MF polymer on the surface of oil particles at a lower $\mathrm{pH}$ value ranging from 3-5 as shown under Step 2. For this reason the $\mathrm{pH}$ value of the mixture was modified to 3-4 with citric acid solution to initiate the in-situ polymerization process. Meanwhile the prepolymer solution was added 
onto the $\mathrm{O} / \mathrm{W}$ emulsion at a stirring speed of $300 \mathrm{rpm}$ with a magnetic stirrer (type IKA HS-7, Germany) and was maintained at a reaction temperature of $70^{\circ} \mathrm{C}$ for 4 hours. The resultant microcapsules were finally filtered, washed with tap water and then dried in an oven at a temperature of $60^{\circ} \mathrm{C}$ for 20 hours.

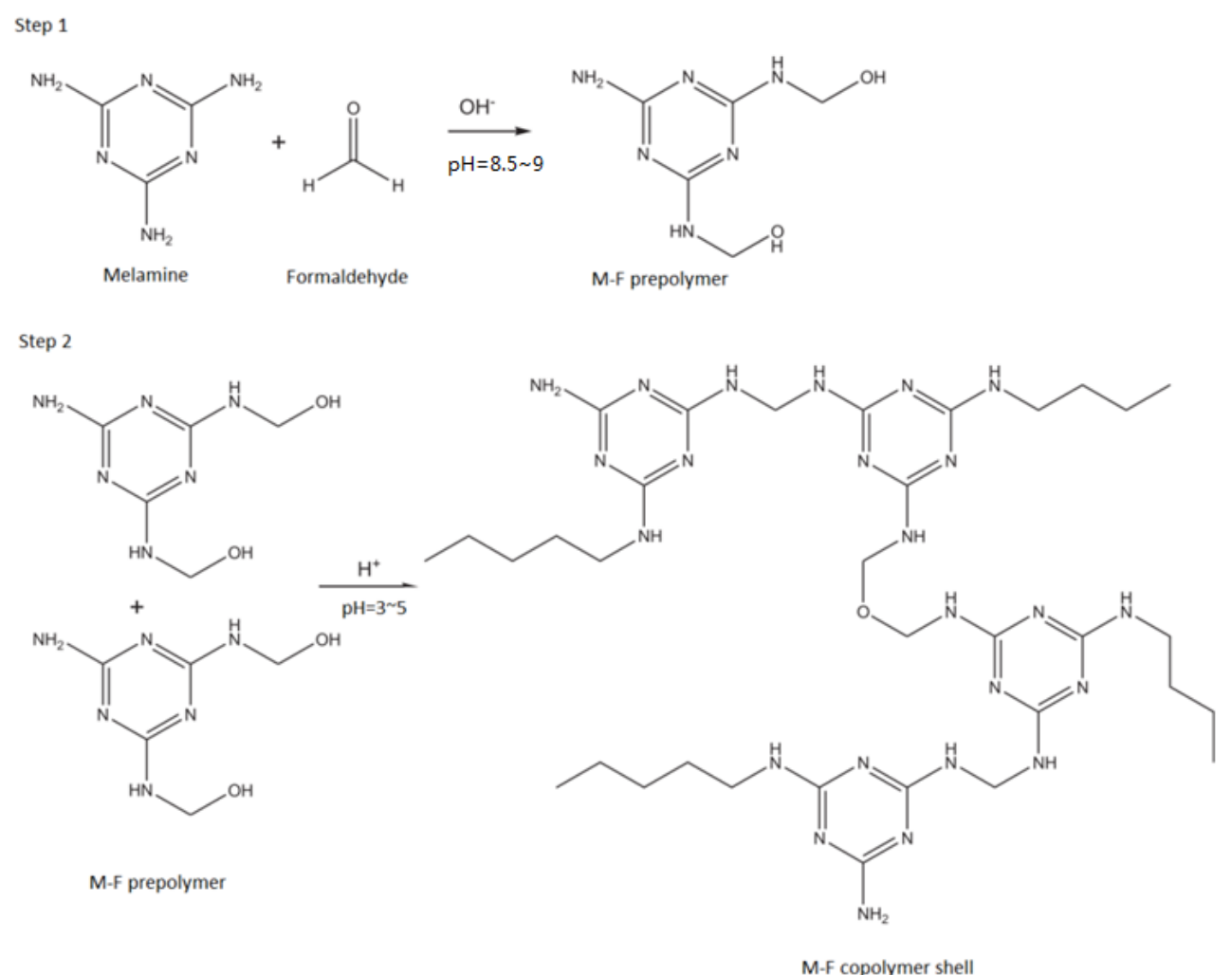

Figure 2: Reaction scheme of melamine-formaldehyde copolymer [11]

Table 1: Reactants and PCM contents for MEPCM fabrication

\begin{tabular}{llllll}
\hline Sample No & Melamine (g) & $\begin{array}{l}\text { Formaldehyde } \\
\text { solution (g) }\end{array}$ & $\begin{array}{l}\text { Paraffin } \\
\text { wax (g) }\end{array}$ & Emulsifiers & $\begin{array}{l}\text { Emulsifiers } \\
\text { Weight (g) }\end{array}$ \\
\hline MEPCM 1 & 4.04 & 6.5 & 10 & SDS & 0.5 \\
MEPCM 2 & 4.04 & 6.5 & 10 & Brij30:Brij 58 & $0.33: 0.17$ \\
\hline
\end{tabular}

\section{Results and analysis}

\section{A. Energy storage capacity evaluation}

Differential scanning calorimetric (DSC6220, SII Nanotechnology) equipment was used in determining the enthalpies of fusion and melting temperature of the MEPCM samples in accordance with ISO 11357 Standards under the dynamic testing method. They were tested under atmospheric pressure and at a heating rate of $2{ }^{\circ} \mathrm{C} / \mathrm{min}$ from $10{ }^{\circ} \mathrm{C}$ to $65{ }^{\circ} \mathrm{C}$. As shown in Fig. 3, the melting enthalpies of pure paraffin, MEPCM 1 and MEPCM 2 were obtained as $194 \mathrm{~kJ} / \mathrm{kg}, 126 \mathrm{~kJ} / \mathrm{kg}$ and $104 \mathrm{~kJ} / \mathrm{kg}$, respectively. Therefore the percentage of core material can be calculated based on the enthalpies of microcapsules and pure paraffin as 65\% for MEPCM 1 and 54\% for MEPCM 2. Meanwhile, the process of microencapsulation had very minimal effect on the melting temperatures of the 
developed samples with slight reductions of 0.68 and $0.95{ }^{\circ} \mathrm{C}$ for MEPCM 1 and MEPCM 2 respectively as summarized in Tab. 2.

Apart from determination of core material content, the DSC thermograms can be used to evaluate the encapsulation efficiency of MEPCM and thereby enabling core material content to be established after fabrication. It is defined as the ratio of the actual core content of the microcapsules to the theoretical core content [15]. For the developed samples the initial core/shell weight ratio was $2: 1$ so based on core material contents of $65 \%$ and $54 \%$, the encapsulation efficiency of MEPCM 1 and MEPCM 2 can be obtained as $97.42 \%$ and $80.41 \%$ respectively.

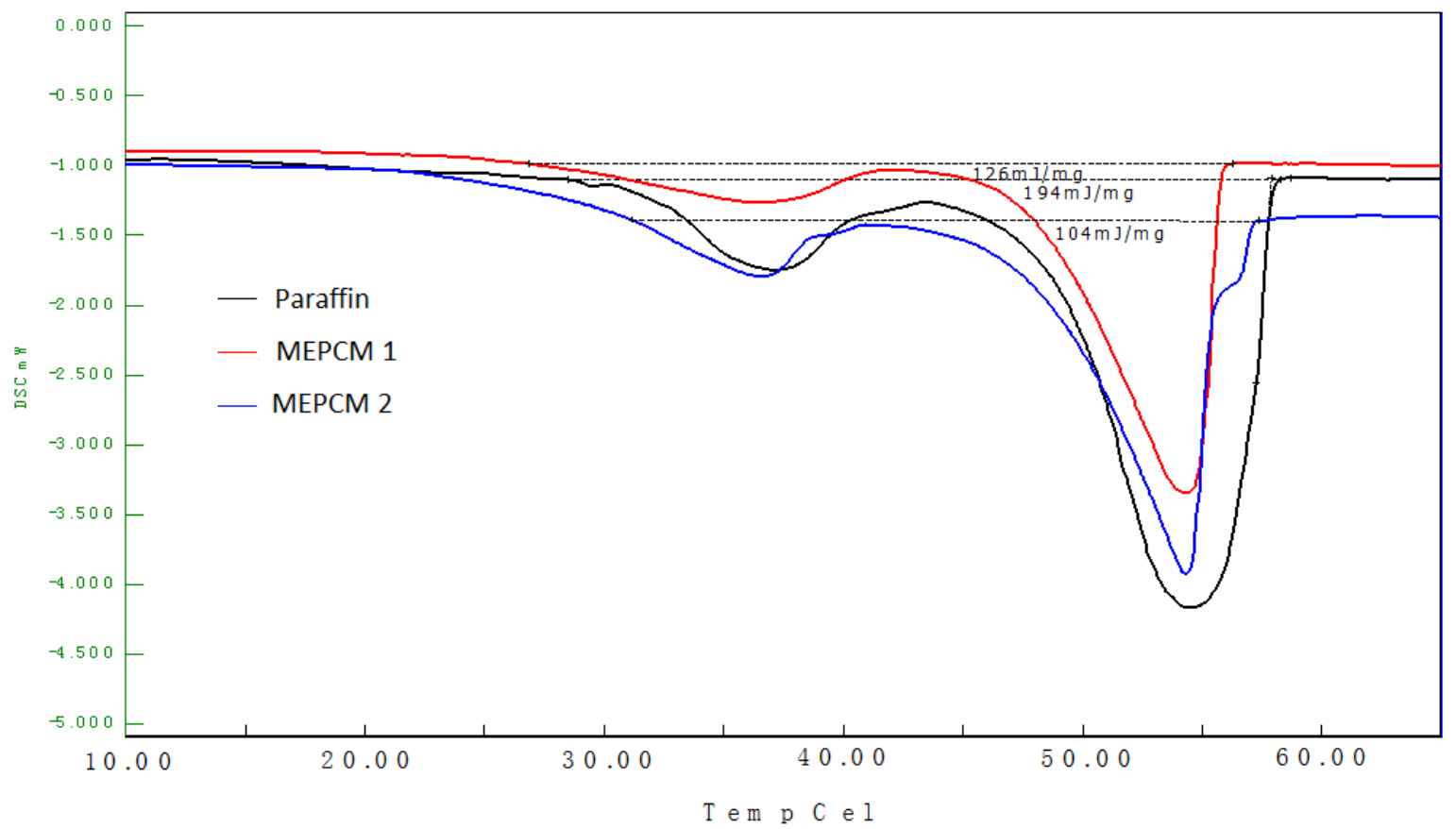

Figure 3: DSC analysis of pure paraffin, MEPCM 1 and MEPCM 2

\section{B. MEPCM thermal stability evaluation}

Thermal stabilities of the MEPCMs were examined by Thermogravimetric (EXSTAR6000 TG/DTA6300, SII Nanotechnology) analysis. The TG tests for this study were carried out under nitrogen gas protection covering a heating range of $50{ }^{\circ} \mathrm{C}$ to $500{ }^{\circ} \mathrm{C}$ and at a heating rate of $10^{\circ} \mathrm{C} / \mathrm{min}$. The analysis results showed thermal stability of MEPCMs were enhanced by microencapsulation process, as summarized in Tab. 2. However, because melamineformaldehyde resin has melting a temperature of $180^{\circ} \mathrm{C}$, the shell might not be able to maintain solid state when the paraffin starts to evaporate at the temperature of $238^{\circ} \mathrm{C}$.

Table 2: Thermal properties of paraffin, MEPCM 1 and MEPCM 2

\begin{tabular}{llllll}
\hline Name & $\begin{array}{l}\text { Melting } \\
\text { temperature }\left({ }^{\circ} \mathrm{C}\right)\end{array}$ & $\begin{array}{l}\mathrm{H} \\
(\mathrm{kJ} / \mathrm{kg})\end{array}$ & Core ratio $(\%)$ & $\begin{array}{l}\text { Encapsulation } \\
\text { efficiency }(\%)\end{array}$ & $\begin{array}{l}\text { Weight } \\
\text { temperature }\left({ }^{\circ} \mathrm{C}\right)\end{array}$ \\
\hline Paraffin & 48.34 & 194 & - & - & 238.0 \\
MEPCM 1 & 47.66 & 126 & $65 \%$ & $97.42 \%$ & 279.6 \\
MEPCM 2 & 47.39 & 104 & $54 \%$ & $80.41 \%$ & 272.2 \\
\hline
\end{tabular}




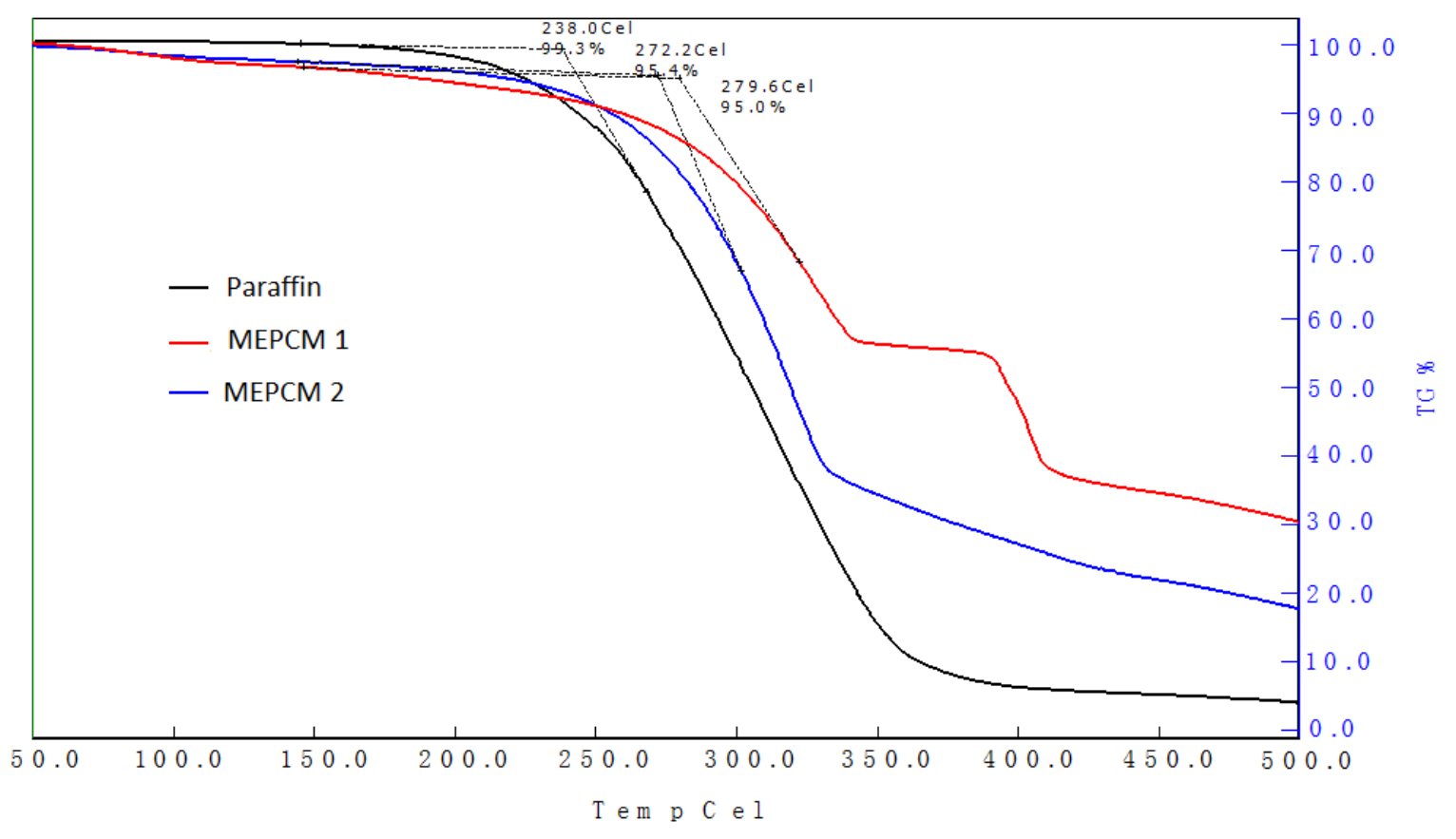

Figure 4: TG analysis of pure paraffin, MEPCM 1 and MEPCM 2

\section{Emulsifier effect on MEPCM fabrication}

The particle sizes and MEPCMs morphology were examined with a scanning electron microscope (SEM; Sigma VP, Zeiss). All samples were coated with a layer of gold prior to the observation. As shown in Fig. 5, the particle size distribution is about $2 \mathrm{um}$. However, the morphology of those two samples showed a significant difference that was caused by the emulsifier type and the amount of HLB that were used during fabrication. In Fig. 5a (MEPCM1), a higher HLB value of anionic emulsifier SDS was used for the fabrication process which resulted in high encapsulation efficiency with serious agglomeration problem. In Fig. 5b (MEPCM2), low HLB value of nonionic mixed emulsifiers (Brij $30+$ Brij 58) and resulted a much better morphology, but the core material content and encapsulation efficiency were much lower. Some of the capsules in sample 2 were also not fully encapsulated which caused the core material to leak out after melting and resulted in low encapsulation efficiency.

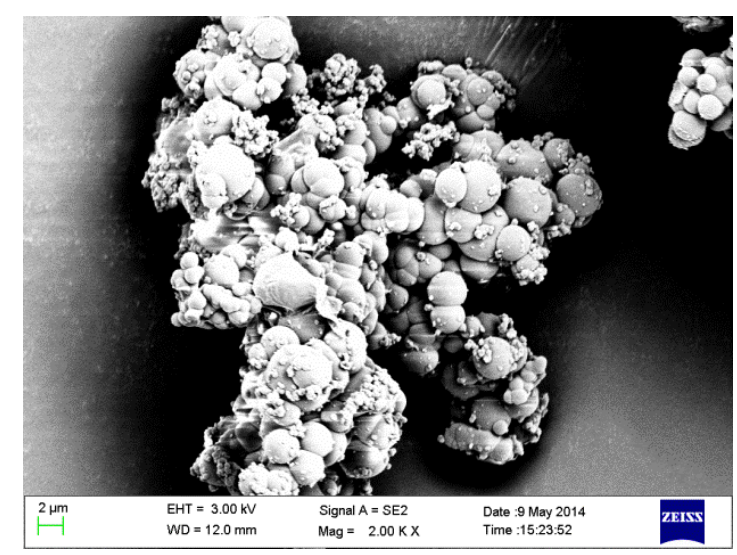

(a) MEPCM 1

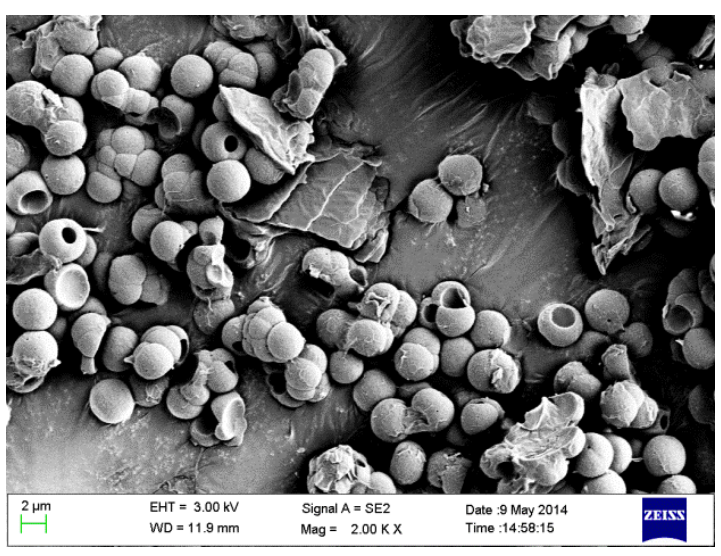

(b) MEPCM 2

Figure 5: SEM examination of MEPCM 1 and MEPCM 2 


\section{Theoretical analysis of TES unit energy storage}

Previous research by Darkwa et. al [16] proved that compression technology can be used to increase energy storage density and effective thermal conductivity. The DSC analysis showed the energy storage capacity of MEPCM 1 and MEPCM 2 as $126 \mathrm{~kJ} / \mathrm{kg}$ and $104 \mathrm{~kJ} / \mathrm{kg}$ respectively. Therefore the energy storage density of the TES unit over a range of 40 to $60{ }^{\circ} \mathrm{C}$ with different weight percentage of MPECM can be calculated with Eq. 1 and be presented graphically as shown in Fig. 6 . In comparison with pure water the maximum energy storage density increased by $98 \%$ for the MEPCM 1 and $71 \%$ for MEPCM 2.

$$
H=w t_{w} \cdot C p_{w} \cdot \Delta T+w t_{P C M} \cdot\left(C p_{P C M} \cdot \Delta T+H_{P C M}\right)+w t_{s} \cdot C p_{s} \cdot \Delta T
$$

Where

$w t_{w}, w t_{P C M}$ and $w t_{s}$ is the weight percentage of water, core material and shell material

$C p_{w}, C p_{P C M}$ and $C p_{s}$ is the specific heat of water, core material and shell material

The effective thermal conductivity can also be calculated by considering the conductivity and the volume fraction components. Thiele et al. [17] proved that the effective thermal conductivity model reported by Felske [18] in Eq. 2 could be applied to core-shell particles in continuous matrix. Therefore using Eq. 2 and data listed in Tab.3, the effective thermal conductivity on volume percentage basis can be calculated and presented graphically as shown in Fig. 6.

$$
k_{e}=\frac{2 k_{w}\left(1-\varphi_{S}-\varphi_{P C M}\right)\left(3+2 \frac{\varphi_{S}}{\varphi_{P C M}}+\frac{\varphi_{S} k_{P C M}}{\varphi_{C} k_{S}}\right)+\left(1+2 \varphi_{P C M}+2 \varphi_{S}\right)\left[\left(3+\frac{\varphi_{S}}{\varphi_{P C M}}\right) k_{P C M}+2 \frac{\varphi_{S} k_{S}}{\varphi_{P C M}}\right]}{\left(2+\varphi_{S}+\varphi_{P C M}\right)\left(3+2 \frac{\varphi_{S}}{\varphi_{P C M}}+\frac{\varphi_{S} k_{P C M}}{\varphi_{C} k_{S}}\right)+\left(1-\varphi_{S}-\varphi_{P C M}\right)\left[\left(3+\frac{\varphi_{S}}{\varphi_{P C M}}\right) \frac{k_{P C M}}{k_{w}}+2 \frac{\varphi_{S} k_{S}}{\varphi_{P C M} k_{w}}\right]}
$$

Where

$k_{m}, k_{P C M}$ and $k_{s}$ is the conductivity of water, paraffin and shell material

$\varphi_{S}$ and $\varphi_{P C M}$ is the volume percentage of shell material and core material

The graphical results show that the higher the weight percentage of MEPCM, the larger the energy storage density but the effective thermal conductivity would reduce. Therefore, the energy storage density and thermal conductivity of TES media should be optimized in accordance with weight percentage of MEPCM in the unit. For example if 50$60 \mathrm{wt} \%$ MEPCM 1 was to be used the energy storage density would increase from $49-59 \%$ in comparison with water. The effective thermal conductivity of $\left(\mathrm{k}_{\mathrm{e} 1}\right)$ would also increase from $0.40-0.36 \mathrm{~W} / \mathrm{m} \cdot \mathrm{K}$ which is about 2 times of pure paraffin.

Table 3: Specific properties of TES components

\begin{tabular}{llll}
\hline Name & Density $\left(\mathrm{kg} / \mathrm{m}^{3}\right)$ & $\mathrm{Cp}(\mathrm{J} / \mathrm{kg} \bullet \mathrm{K})$ & Thermal conductivity $(\mathrm{W} / \mathrm{m} \bullet \mathrm{K})$ \\
\hline Water & 1000 & 4200 & 0.62 \\
Paraffin & 800 & 2500 & 0.2 \\
MF resin & 1500 & 1200 & 0.35 \\
\hline
\end{tabular}




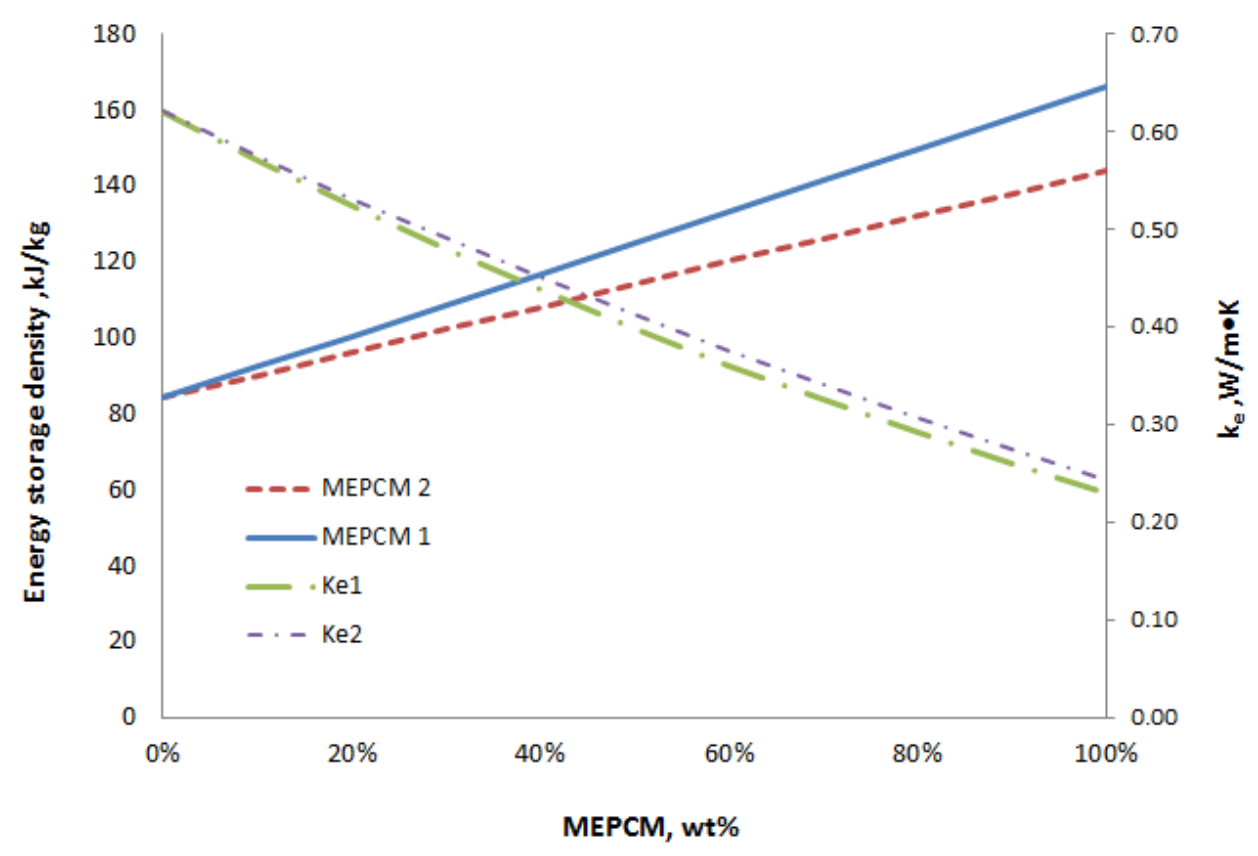

Figure 6: Thermal properties of TES unit

\section{Conclusions}

The study was intended to development of a high melting temperature MEPCM as a thermal energy storage media for solar hot water storage application. Based on paraffin as the core material and MF resin as the shell material samples of MEPCM have been successfully fabricated by in-situ polymerization method and tested.. The morphological results showed that the core material content and encapsulation efficiency were strongly influenced by the emulsifiers as summarized in Tab. 2. For instance type SDS emulsifier and $65 \%$ core material content were used to produce a higher melting temperature MEPCM 1 (from $48.34^{\circ} \mathrm{C}$ to $47.66^{\circ} \mathrm{C}$ ) and at relatively high encapsulation efficiency of $97.42 \%$. The TG test showed that some weight loss started to occur when the temperatures of the samples were increased by more than $34^{\circ} \mathrm{C}$ after encapsulation. However, the theoretical analysis indicated that energy storage density can be increased from $49 \%$ to $59 \%$ with corresponding increase in thermal conductivity from 0.40 to $0.36 \mathrm{~W} / \mathrm{m} \bullet \mathrm{K}$ if $50-60 \mathrm{wt} \%$ of MEPCM 1 is used in the proposed TES unit. In general the study has demonstrated the potential of the developed sample for thermal energy storage applications.

\section{References}

1. Kozak, Y., Rozenfeld, T., and Ziskind, G. "Close-contact melting in vertical annular enclosures with a non-isothermal base: Theoretical modeling and application to thermal storage," International Journal of Heat and Mass Transfer Vol. 72, No. 0, 2014, pp. 114-127.

doi: http://dx.doi.org/10.1016/j.ijheatmasstransfer.2013.12.058

2. $\quad$ Murray, R. E., and Groulx, D. "Experimental study of the phase change and energy characteristics inside a cylindrical latent heat energy storage system: Part 1 consecutive charging and discharging," Renewable Energy Vol. 62, No. 0, 2014, pp. 571-581.

doi: http://dx.doi.org/10.1016/j.renene.2013.08.007

3. Lochan, A., and Arif, M. "Phase Change Materials and Potential Applications," International Journal of Applied Engineering Research Vol. 8, 2013, pp. 2115-2120.

4. $\quad$ Nkwetta, D. N., and Haghighat, F. "Thermal energy storage with phase change material-A state-of-the art review," Sustainable Cities and Society Vol. 10, No. 0, 2014, pp. 87-100.

doi: http://dx.doi.org/10.1016/j.scs.2013.05.007

5. López-Navarro, A., Biosca-Taronger, J., Corberán, J. M., Peñalosa, C., Lázaro, A., Dolado, P., and Payá, J. "Performance characterization of a PCM storage tank," Applied Energy Vol. 119, No. 0, 2014, pp. 151-162.

doi: http://dx.doi.org/10.1016/j.apenergy.2013.12.041

American Institute of Aeronautics and Astronautics 
6. Behzadi, S., and Farid, M. M. "Long term thermal stability of organic PCMs," Applied Energy Vol. 122, No. 0, 2014, pp. 11-16.

doi: http://dx.doi.org/10.1016/j.apenergy.2014.01.032

7. $\quad$ Chen, S.-L., Chen, C.-L., Tin, C.-C., Lee, T.-S., and Ke, M.-C. "An experimental investigation of cold storage in an encapsulated thermal storage tank," Experimental Thermal and Fluid Science Vol. 23, No. 3-4, 2000, pp. 133-144.

doi: http://dx.doi.org/10.1016/S0894-1777(00)00045-5

8. Jamekhorshid, A., Sadrameli, S. M., and Farid, M. "A review of microencapsulation methods of phase change materials (PCMs) as a thermal energy storage (TES) medium," Renewable and Sustainable Energy Reviews Vol. 31, No. 0, 2014, pp. 531-542.

doi: http://dx.doi.org/10.1016/j.rser.2013.12.033

9. Regin, A. F., Solanki, S. C., and Saini, J. S. "Heat transfer characteristics of thermal energy storage system using PCM capsules: A review," Renewable and Sustainable Energy Reviews Vol. 12, No. 9, 2008, pp. 2438-2458.

doi: 10.1016/j.rser.2007.06.009

10. Ho, C. J., Siao, C.-R., and Yan, W.-M. "Thermal energy storage characteristics in an enclosure packed with MEPCM particles: An experimental and numerical study," International Journal of Heat and Mass Transfer Vol. 73, No. 0, 2014, pp. 88-96.

doi: http://dx.doi.org/10.1016/j.ijheatmasstransfer.2014.01.056

11. Cao, F., and Yang, B. "Supercooling suppression of microencapsulated phase change materials by optimizing shell composition and structure," Applied Energy Vol. 113, No. 0, 2014, pp. 1512-1518.

doi: http://dx.doi.org/10.1016/j.apenergy.2013.08.048

12. Choi, J. K., Lee, J. G., Kim, J. H., and Yang, H. S. "Preparation of microcapsules containing phase change materials as heat transfer media by in-situ polymerization," Journal of Industrial and Engineering Chemistry Vol. 7, No. 6, 2001, pp. 358-362.

13. Hong, K., and Park, S. "Melamine resin microcapsules containing fragrant oil: synthesis and characterization," Materials Chemistry and Physics Vol. 58, No. 2, 1999, pp. 128-131.

doi: http://dx.doi.org/10.1016/S0254-0584(98)00263-6

14. Tadros, T. F. Emulsion Science and Technology: Wiley, 2009.

15. Zhang, H., and Wang, X. "Synthesis and properties of microencapsulated n-octadecane with polyurea shells containing different soft segments for heat energy storage and thermal regulation," Solar Energy Materials and Solar Cells Vol. 93, No. 8, 2009, pp. 1366-1376.

doi: http://dx.doi.org/10.1016/j.solmat.2009.02.021

16. Darkwa, J., Su, O., and Zhou, T. "Development of non-deform micro-encapsulated phase change energy storage tablets," Applied Energy Vol. 98, 2012, pp. 441-447.

doi: 10.1016/j.apenergy.2012.04.006

17. Thiele, A. M., Kumar, A., Sant, G., and Pilon, L. "Effective thermal conductivity of three-component composites containing spherical capsules," International Journal of Heat and Mass Transfer Vol. 73, No. 0, 2014, pp. 177-185.

doi: http://dx.doi.org/10.1016/j.ijheatmasstransfer.2014.02.002

18. Felske, J. D. "Effective thermal conductivity of composite spheres in a continuous medium with contact resistance," International Journal of Heat and Mass Transfer Vol. 47, No. 14-16, 2004, pp. 3453-3461.

doi: http://dx.doi.org/10.1016/j.ijheatmasstransfer.2004.01.013 